\title{
Expression of the Yes-Associated Protein, $\beta$-Catenin, and Smoothened Protein and Their Clinical Significance in Invasive Breast Cancer
}

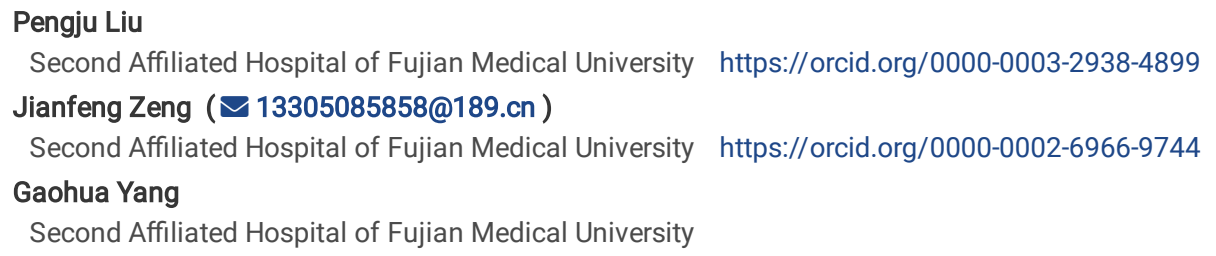

\section{Research}

Keywords: Yes-associated protein, $\beta$-catenin, Smoothened protein, Breast cancer

Posted Date: November 1st, 2021

DOI: https://doi.org/10.21203/rs.3.rs-1010969/v1

License: () (i) This work is licensed under a Creative Commons Attribution 4.0 International License. Read Full License 


\section{Abstract}

Background: The mechanism of the Yes-associated protein in the occurrence and development of breast cancer is still unclear. Here, we aimed to explore the relationship among the Yes-associated protein, $\beta$-catenin, and Smoothened signaling pathways to provide a theoretical basis for the clinical diagnosis and Treatment program of invasive breast cancer.

Methods: Immunohistochemistry was used to detect the expression of Yes-associated protein, Smoothened protein, and $\beta$-catenin in breast cancer, adjacent, and normal tissues. The relationship between the expression of these three proteins and clinicopathological features of breast cancer patients was analyzed, and western blotting was used to detect differences in Yes-associated protein expression in MCF-7 and MDA-MB-231 cell lines.

Results: The expression level of Yes-associated protein in breast cancer tissues was prominently Lower than that in normal breast tissues; the expression level of $\beta$-catenin in breast cancer tissues was prominently higher than that in normal tissues; and the expression level of Smoothened protein in cancer tissue was Prominently higher than that in normal breast tissue. The expression of Yes-associated protein in breast cancer tissues was correlated with the expression of the human epidermal growth factor receptor 2 , progesterone receptor, and estrogen receptor; the expression of $\beta$-catenin and Smoothened protein in breast cancer tissues were all correlated with the human epidermal growth factor receptor expression. The expression level of Yes-associated protein in the MCF-7 cells was significantly higher than that in the MDA-MB-231 cells. There was a negative correlation between the Yes-associated protein and Smoothened protein expression in the breast cancer tissues.

Conclusions: The Yes-associated protein, $\beta$-catenin, and Smoothened protein can be used as new targets in the treatment of invasive breast cancer or as reference indicators for prognostic judgment. The differences in expression of the three proteins in cancer adjacent, cancer, and normal tissues suggest that they may be of great significance in the process of breast-conserving surgery.

\section{Introduction}

Breast cancer has become the most prevalent cancer in the world in the 21 st century, accounting for $11.6 \%$ of the total cancer incidence and $6.6 \%$ of the total cancer deaths ${ }^{[1]}$. Therefore, searching for molecular markers that can effectively predict the progression and prognosis of breast cancer is of great significance for the prevention and treatment of breast cancer.

Some researchers have proved that the occurrence, development, and metastasis of breast cancer are closely related to cancer stem cells ${ }^{[2,3]}$. Among the main signaling pathways in tumor stem cells are the Wnt and Hedgehog signaling pathways, and the relationship between them plays a important role in tumor biological behavior ${ }^{[4]}$. The self-renewal and differentiation process of breast cancer stem cells is also regulated by these two major signaling pathways ${ }^{[3]}$.

Wnt signaling pathway has great significance in controlling embryonic and organ development and cancer progression. Genome wide sequencing and gene expression profile showed that the Wnt pathway is involved in the proliferation and metastasis of breast cancer, and Wnt/ $\beta$-catenin signaling pathway is one of the most characteristic pathway ${ }^{[5]}$. Downregulated $\beta$-catenin blocks the activation of $\mathrm{Wnt} / \beta$-catenin pathway, inhibiting the invasion and migration of breast cancer cells ${ }^{[6,7]}$. The Hedgehog signaling pathway is involved in regulating the occurrence of early breast cancer, and activating Hedgehog pathway can enhance the metastasis and invasiveness of breast cancer cells ${ }^{[8]}$. Smoothened (SMO) is one of the constituent proteins of the Hedgehog signaling pathway, and the Hedgehog protein family consists of sonic hedgehog (SHH), Indian hedgehog (IHH), and desert hedgehog (DHH), which bind to the cell surface as a transmembrane protein receptor, Patched (PTCH). When the Hedgehog ligand is missing, PTCH inhibits Hedgehog signaling by inhibiting the activity of SMO. In contrast, when the Hedgehog ligand binds to the $\mathrm{PTCH}$ receptor, the SMO receptor is released and activates the cytoplasmic glioma-associated oncogene homologue (GLI) family zinc finger transcription factors (Glil-3), thereby activating the Hedgehog pathway ${ }^{[9,10]}$. The Hippo signaling pathway is a highly conserved signaling pathway discovered in Drosophila cells during Drosophila genetic screening in the 1990s, which plays a key role in controlling organ growth, regeneration, and tumor suppression ${ }^{[11]}$. The Yes-associated protein (YAP) is a true effector of the Hippo signaling pathway, and it is overexpressed in many kinds of cancers and is considered to be encoded by proto-oncogenes, Increasing Yap activity can accelerate the progression of cancer ${ }^{[12]}$. However, the role of YAP in breast cancer remains controversial because the increase and decrease in YAP expression in breast cancer have been reported in many studies $^{[13]}$, and recent studies have found that there is a cross-relationship between the Hippo and Wnt pathway. In basal-like breast cancer, YAP and $\beta$-catenin synergistically regulate tumor stem cells to drive breast cancer ${ }^{[14]}$. The overexpression of YAP in breast cancer cells blocks the Hedgehog signaling pathway, and the knockout of YAP in cells can enhance the activity of the Hedgehog pathway. Moreover, Hedgehog signaling can promote YAP activity through a posttranscriptional mechanism, which leads to a negative feedback loop ${ }^{[15]}$.

Thus, in this study, by exploring the expression and correlation of YAP, SMO, and $\beta$-catenin in breast cancer, we aimed to verify whether the three signaling pathways could be combined with one other for the clinical diagnosis, treatment, and prognosis evaluation of invasive breast cancer.

\section{Methods}

\section{Tissue samples}

The pathological tissue wax blocks of breast cancer patients surgically resected in the Second Affiliated Hospital of Fujian Medical University from January 2020 to January 2021 were selected, and those who had complete clinical records and pathological data were included in the study, for a total of 60 cases. Samples from patients who had received neoadjuvant chemotherapy were excluded..The 60 cancerous tissues were all invasive cancers and were designated as the breast cancer group, whereas 60 cases of paracancerous tissues (breast tissue $2 \mathrm{~cm}$ from the edge of the cancerous tissue) and 60 normal breast tissues (breast tissue more than $5 \mathrm{~cm}$ away from the edge of cancer tissue and without cancer cell infiltration confirmed by pathology) from these 60 patients 
were selected as the control group. All the patients were female, aged 31-73 years old (49.97 \pm 10.25$)$, and underwent modified radical mastectomy after breast cancer diagnosis through pathological analysis in our hospital. The breast cancer specimens were all diagnosed by two pathologists and were reviewed by the chief pathologist. The research project complied with the Declaration of Helsinki, and the tissue wax sampling of this experiment was approved by the ethics committee of the Second Affiliated Hospital of Fujian Medical University. Informed consent was taken from all the patients. The clinicopathological data of 60 patients with breast cancer are shown in Table 1.

Table 1

Clinicopathological features of 60 patients with invasive breast cancer

\begin{tabular}{|c|c|c|}
\hline Clinicopathological features & $\mathbf{n}$ & constituent ratio/\% \\
\hline \multicolumn{3}{|l|}{ Age } \\
\hline$>50$ & 28 & 46.7 \\
\hline$<50$ & 32 & 53.3 \\
\hline \multicolumn{3}{|l|}{ Histological grade } \\
\hline I & 1 & 1.7 \\
\hline II & 27 & 45 \\
\hline III & 32 & 53.3 \\
\hline \multicolumn{3}{|l|}{ Tumor size/cm } \\
\hline$<2$ & 21 & 35 \\
\hline $2-5$ & 36 & 60 \\
\hline$>5$ & 3 & 5 \\
\hline \multicolumn{3}{|l|}{ Lymph node metastasis/n } \\
\hline 0 & 34 & 56.7 \\
\hline $1-3$ & 15 & 25 \\
\hline $4-9$ & 7 & 11.6 \\
\hline$\geq 10$ & 4 & 6.7 \\
\hline \multicolumn{3}{|l|}{ Her-2 } \\
\hline Positive & 22 & 36.7 \\
\hline Negative & 38 & 63.3 \\
\hline \multicolumn{3}{|l|}{ ER } \\
\hline Positive & 41 & 68.3 \\
\hline Negative & 19 & 31.7 \\
\hline \multicolumn{3}{|l|}{ PR } \\
\hline Positive & 40 & 66.7 \\
\hline Negative & 20 & 33.3 \\
\hline \multicolumn{3}{|l|}{ Ki67 } \\
\hline Positive & 42 & 70 \\
\hline Negative & 18 & 30 \\
\hline \multicolumn{3}{|l|}{ Tumor stage } \\
\hline I & 16 & 26.7 \\
\hline II & 33 & 55 \\
\hline III & 11 & 18.3 \\
\hline
\end{tabular}

\section{Main Reagents And Materials Immunohistochemical reagents}


Citric acid ( $\mathrm{pH}$ 6.0) antigen repair solution, phosphate buffer saline, 4 \% paraformaldehyde, bovine serum albumin, hematoxylin stain solution, immunohistochemical kit, 3, 3'-diaminobenzidine (DAB) chromogenic reagent, and normal rabbit serum were purchased from Wuhan Servicebio Technology Co., Ltd. (Wuhan, China).

\section{Western blot reagents}

Horseradish peroxidase (HRP)-conjugated secondary antibody, bicinchoninic acid (BCA) protein quantification kit, sodium dodecyl sulfate polyacrylamide gel electrophoresis (SDS-PAGE), polyvinylidene fluoride (PVDF) membrane, and buffer were purchased from Wuhan Servicebio Technology Co., Ltd.

\section{Cell lines}

The MDA-MB-231 and MCF-7 cell lines used in this experiment were purchased from Procell Life Science \& Technology Co., Ltd. and cultured in an incubator at $37^{\circ} \mathrm{C}, 5 \%$ carbon dioxide, and saturated humidity.

\section{Immunohistochemical Staining}

The paraffin sections were deparaffinized and rehydrated. For the antigen retrieval, the tissue sections were placed in a repair box filled with citric acid ( $\mathrm{pH} 6.0$ ) antigen retrieval buffer for antigen retrieval in a microwave oven. This blocked the endogenous peroxidase activity, and then blocking serum was added. Then, primary antibody and secondary antibody incubation were performed. To stain the sections, DAB was used, which were counterstained with hematoxylin stain solution, and then dehydration and mounting were performed. Finally, the stained tissue sections were visualized under a microscope and images were acquired for analysis.

\section{Scoring criteria}

For the staining intensity score ${ }^{[16]}$, the following were applied: 0 points for no coloring, 1 point for light yellow, 2 points for brownish-yellow, and 3 points for brown. For the scoring based on the positive rate of cells, the following were applied: $0-5 \%$ is 0 points, $6-25 \%$ is 1 point, $26-50 \%$ is 2 points, $51-75 \%$ is 3 points, and $>75 \%$ is 4 points. The staining intensity score $\times$ the positive cell ratio score is the comprehensive staining score, wherein: 0 is negative, $1-3$ points are weakly positive, 4-8 points are moderately strong positive (++), and $9-12$ points are strongly positive (+++), of which $0-3$ points are judged as low expression level, and $>4$ points are judged as high expression level.

\section{Western Blot}

The total cellular protein was extracted using the BCA protein quantification kit for protein quantification, which was denatured by boiling water for 15 min. Then, the sample was loaded on a $12 \%$ SDS-PAGE gel for electrophoretic separation. A constant current of 300 was applied on the membrane for half an hour to transfer the protein to the PVDF membrane, which was then blocked with $5 \%$ skim milk and washed with Tris-buffered saline buffer. Then, the membrane was incubated with primary antibody $(1: 1,000)$ and secondary antibody $(1: 5,000)$, and the immunoreactions were observed using enhanced chemiluminescence (ECL) reagent, wherein glyceraldehyde-3-phosphate dehydrogenase (GAPDH) was used as an internal reference. Then, the optical density (OD) values were analyzed using Quantity One software.

\section{Statistical Methods}

SPSS 26.0 and GraphPad Prism 8.0. were used for the statistical analysis. The measurement data was analyzed by paired-sample t-test, and the count data was analyzed by $\chi^{2}$ test. The Spearman's correlation analysis method was used for correlation analysis. GraphPad, PS, and other software were used for the chart production.

\section{Results}

\section{Differential expression of YAP, $\beta$-catenin, and SMO in breast cancer, paracancerous, and normal breast tissues}

The expression trend of YAP in the three tissues is shown in Figure 1, which was statistically significant $\left(\chi^{2}=11.2, P=0.0037\right)$. Further pairwise comparison showed that The expression level of Yes-associated protein in breast cancer tissues was prominently Lower than that in normal breast tissues $\left(\chi^{2}=7.232, P=\right.$ 0.007)(Fugure 2 and Table 2). The expression of YAP in the adjacent breast cancer tissues showed a downward trend compared with that in the normal tissues, and there was no statistical difference $(P>0.05)$ (Fugure 2 and Table 2). 
Table 2

YAP expression in breast cancer tissue, Paracancerous tissue and normal tissue. ${ }^{*}, \mathrm{P}<0.05$ compared with Normal tissue

\begin{tabular}{|lllllll|}
\hline group & $\mathbf{n}$ & YAP & & \multirow{2}{*}{ X } & P \\
\cline { 3 - 6 } & & High expression & Low expression & High expression rate & & \\
\hline Normal tissue & 60 & 44 & 16 & 73.3 & 2.4 & 0.121 \\
\hline Paracancerous tissue & 60 & 36 & 24 & 60 & 2.337 & 0.068 \\
\hline Cancer tissue & 60 & 26 & 34 & 43.3 & 11.109 & $0.001^{*}$ \\
\hline
\end{tabular}

The expression trend of $\beta$-catenin in the three tissues is shown in Figure 1, which was statistically significant $\left(\chi^{2}=7.232, P=0.007\right)$. Further pairwise comparison showed that the expression of $\beta$-catenin in the breast cancer tissues was higher than that in the normal tissues $\left(\chi^{2}=6.207, P=0.013\right)($ Fugure 2 and Table 3). The expression of $\beta$-catenin in the Paracancerous tissue showed an upward trend compared with that in the normal tissues, and there was no statistical difference $(P>0.05)$ (Fugure 2 and Table 3 ).

Table 3

$\beta$-catenin expression in breast cancer tissue, Paracancerous tissue and normal tissue.* $\mathrm{P}<0.05$ compared with Normal tissue

\begin{tabular}{|c|c|c|c|c|c|c|}
\hline \multirow[t]{2}{*}{ group } & \multirow[t]{2}{*}{$\mathbf{n}$} & \multicolumn{3}{|l|}{$\beta$-catenin } & \multirow[t]{2}{*}{$x^{2}$} & \multirow[t]{2}{*}{$\mathbf{P}$} \\
\hline & & High expression & Low expression & High expression rate & & \\
\hline Normal tissue & 60 & 28 & 32 & 46.7 & 1.201 & 0.273 \\
\hline Paracancerous tissue & 60 & 34 & 26 & 56.7 & 3.663 & 0.056 \\
\hline Cancer tissue & 60 & 44 & 16 & 73.3 & 8.889 & $0.003^{*}$ \\
\hline
\end{tabular}

The expression trend of SMO in the three tissues is shown in Figure 1 , which was statistically significant $\left(\chi^{2}=7.825, P=0.02\right)$. Further pairwise comparison showed that the expression of SMO in the breast cancer tissues was higher than that in the normal tissues $\left(\chi^{2}=6.207, P=0.013\right)($ Fugure 2 and Table 4). The expression of SMO in the Paracancerous tissue showed an upward trend compared with that in the normal tissues, and there was no statistical difference( $P>0.05$ )(Fugure 2 and Table 4).

Table 4

Smo expression in breast cancer tissue, Paracancerous tissue and normal tissue.*, $\mathrm{P}<0.05$ compared with

\begin{tabular}{|c|c|c|c|c|c|c|}
\hline \multirow{3}{*}{ group } & \multirow{3}{*}{$\mathrm{n}$} & \multicolumn{3}{|c|}{ Normal tissue } & \multirow{3}{*}{$x^{2}$} & \multirow{3}{*}{$\mathbf{P}$} \\
\hline & & SMO & & & & \\
\hline & & High expression & Low expression & High expression rate & & \\
\hline Normal tissue & 60 & 24 & 36 & 40 & 3.337 & 0.068 \\
\hline Paracancerous tissue & 60 & 34 & 26 & 56.7 & 0.874 & 0.35 \\
\hline Cancer tissue & 60 & 39 & 21 & 65 & 7.519 & $0.006^{*}$ \\
\hline
\end{tabular}

Relationship between the expression of YAP, $\beta$-catenin, and SMO of breast cancer patients and clinicopathological features

The expression of YAP in the breast cancer tissues was not correlated with age, histological grade, tumor size, lymph node metastasis, Ki67 index, and tumor stage of the breast cancer patients $(P>0.05)$ and was significantly correlated with the human epidermal growth factor receptor $2\left(\right.$ Her-2) $\left(\chi^{2}=8.735, P=0.003\right)$, progesterone receptor $(\mathrm{PR})\left(\chi^{2}=5.735, P=0.017\right)$, and estrogen receptor $(E R)\left(X^{2}=4.45, P=0.035\right)($ Table 5$)$. 
Table 5

Relationship between the expression of $\mathrm{YAP} \square \beta$-catenin and SMO of breast cancer patients and clinicopathological features. ${ }^{*}, \mathrm{P}<0.05$

\begin{tabular}{|c|c|c|c|c|c|c|c|c|c|c|c|c|c|}
\hline \multirow[t]{2}{*}{ Gourp } & \multirow[t]{2}{*}{$\mathrm{n}$} & \multicolumn{2}{|l|}{ YAP } & \multirow[t]{2}{*}{$x^{2}$} & \multirow[t]{2}{*}{$\mathrm{P}$} & \multicolumn{2}{|l|}{$\beta$-catenin } & \multirow[t]{2}{*}{$x^{2}$} & \multirow[t]{2}{*}{$P$} & \multicolumn{2}{|l|}{ SMO } & \multirow[t]{2}{*}{$\chi^{2}$} & \multirow[t]{2}{*}{$\mathrm{F}$} \\
\hline & & $\begin{array}{l}\text { High } \\
\text { expression }\end{array}$ & $\begin{array}{l}\text { Low } \\
\text { expression }\end{array}$ & & & $\begin{array}{l}\text { High } \\
\text { expression }\end{array}$ & $\begin{array}{l}\text { Low } \\
\text { expression }\end{array}$ & & & $\begin{array}{l}\text { High } \\
\text { expression }\end{array}$ & $\begin{array}{l}\text { Low } \\
\text { expression }\end{array}$ & & \\
\hline Age & & & & 0.95 & 0.33 & & & 0.357 & 0.55 & & & 0.012 & 0 \\
\hline$>50$ & 28 & 14 & 14 & & & 22 & 6 & & & 18 & 10 & & \\
\hline$<50$ & 32 & 12 & 20 & & & 23 & 9 & & & 21 & 11 & & \\
\hline $\begin{array}{l}\text { Histological } \\
\text { grade }\end{array}$ & & & & 1.002 & 0.606 & & & 3.775 & 0.152 & & & 0.659 & 0 \\
\hline I & 1 & 0 & 1 & & & 0 & 1 & & & 1 & 0 & & \\
\hline II & 27 & 11 & 16 & & & 22 & 5 & & & 18 & 9 & & \\
\hline III & 32 & 15 & 17 & & & 23 & 9 & & & 20 & 12 & & \\
\hline $\begin{array}{l}\text { Tumor } \\
\text { size/cm }\end{array}$ & & & & 0.158 & 0.749 & & & 1.164 & 0.559 & & & 1.863 & 0 \\
\hline$<2$ & 21 & 8 & 13 & & & 16 & 5 & & & 16 & 5 & & \\
\hline $2-5$ & 36 & 17 & 19 & & & 26 & 10 & & & 21 & 15 & & \\
\hline$>5$ & 3 & 1 & 2 & & & 3 & 0 & & & 2 & 1 & & \\
\hline $\begin{array}{l}\text { Lymph } \\
\text { node } \\
\text { metastasis }\end{array}$ & & & & 2.95 & 0.086 & & & 0.09 & 0.976 & & & 1.316 & 0 \\
\hline No & 34 & 18 & 16 & & & 19 & 7 & & & 20 & 14 & & \\
\hline Yes & 26 & 8 & 18 & & & 26 & 8 & & & 19 & 7 & & \\
\hline Her-2 & & & & 8.735 & $0.003^{\star}$ & & & 11.579 & $0.001^{*}$ & & & 5.833 & 0 \\
\hline Positive & 22 & 15 & 7 & & & 22 & 0 & & & 10 & 12 & & \\
\hline Negative & 38 & 11 & 27 & & & 23 & 15 & & & 29 & 9 & & \\
\hline ER & & & & 4.45 & $0.035^{\star}$ & & & 0.231 & 0.631 & & & 0.041 & 0 \\
\hline Positive & 41 & 14 & 27 & & & 30 & 11 & & & 27 & 14 & & \\
\hline Negative & 19 & 12 & 7 & & & 15 & 4 & & & 12 & 7 & & \\
\hline PR & & & & 5.735 & $0.017 *$ & & & 1.6 & 0.206 & & & 0.33 & 0 \\
\hline Positive & 40 & 13 & 27 & & & 28 & 12 & & & 27 & 13 & & \\
\hline Negative & 20 & 13 & 7 & & & 17 & 3 & & & 12 & 8 & & \\
\hline Ki67 & & & & 1.047 & 0.306 & & & 0.106 & 0.745 & & & 0.031 & 0 \\
\hline Positive & 42 & 20 & 22 & & & 32 & 10 & & & 27 & 15 & & \\
\hline Negative & 18 & 6 & 12 & & & 13 & 5 & & & 12 & 6 & & \\
\hline $\begin{array}{l}\text { Tumor } \\
\text { stage }\end{array}$ & & & & 4.745 & 0.093 & & & 0.616 & 0.735 & & & 3.656 & 0 \\
\hline 1 & 16 & 6 & 10 & & & 11 & 5 & & & 12 & 4 & & \\
\hline ॥ & 33 & 15 & 18 & & & 26 & 7 & & & 18 & 15 & & \\
\hline III & 11 & 9 & 2 & & & 8 & 3 & & & 9 & 2 & & \\
\hline
\end{tabular}

The expression of $\beta$-catenin in the breast cancer tissues was not correlated with age, histological grade, tumor size, lymph node metastasis, Ki67 index, ER, PR, and tumor stage of the breast cancer patients and was significantly correlated with the Her-2( $\left.\chi^{2}=11.579, P=0.001\right)($ Table 5$)$.

The expression of SMO in the breast cancer tissues was not correlated with age, histological grade, tumor size, lymph node metastasis, Ki67 index, ER, PR, and tumor stage of the breast cancer patients and was significantly correlated with the Her-2( $\left.\chi^{2}=5.833, P=0.016\right)($ Table 5$)$.

\section{Differential expression of YAP between the MCF-7 and MDA-MB-2314 cell lines}

The expression of YAP in the MCF-7 cells was significantly higher than that in the MDA-MB-231 cells, and the difference was statistically significant $(\mathrm{t}=4.518$, $P=0.0107)$ (Fugure 3). 
Using Spearman's correlation analysis, no correlation was found between the expression of YAP and $\beta$-catenin in the breast cancer tissues $(r=0.039, P=$ 0.768)(Table 6), the expression of YAP and SMO in the breast cancer tissues was negatively correlated $(r=-0.275, P<0.05)($ Table 7), and there was no correlation between the expression of $\beta$-catenin and $\mathrm{SMO}(r=-0.02, P=0.878)$ (Table 8).

Table 6

Correlation analysis of YAP and $\beta$-catenin expression in breast cancer tissues

\begin{tabular}{|llllll|}
\hline YAP & $\beta$-catenin & & & $r$ & $P$ \\
\cline { 2 - 4 } & High expression & High expression & total & & \\
\cline { 1 - 4 } High expression & 20 & 6 & 26 & 0.039 & 0.768 \\
\cline { 1 - 4 } Low expression & 25 & 9 & 34 & & \\
\cline { 1 - 4 } total & 45 & 15 & 60 & & \\
\hline
\end{tabular}

Table 7

Correlation analysis of YAP and Smo expression in breast cancer tissues.*, $\mathrm{P}<0.05$

\begin{tabular}{|c|c|c|c|c|c|}
\hline \multirow[t]{2}{*}{ YAP } & \multicolumn{3}{|l|}{ SMO } & \multirow[t]{2}{*}{$r$} & \multirow[t]{2}{*}{$\mathrm{P}$} \\
\hline & High expression & High expression & total & & \\
\hline High expression & 13 & 13 & 26 & \multirow[t]{3}{*}{-0.275} & \multirow[t]{3}{*}{$0.033^{*}$} \\
\hline Low expression & 26 & 8 & 34 & & \\
\hline total & 39 & 21 & 60 & & \\
\hline
\end{tabular}

Table 8

Correlation analysis of $\beta$-catenin and Smo expression in breast cancer tissues

\begin{tabular}{|c|c|c|c|c|c|}
\hline \multirow[t]{2}{*}{$\beta$-catenin } & \multicolumn{3}{|l|}{ Smo } & \multirow[t]{2}{*}{$\mathrm{r}$} & \multirow[t]{2}{*}{$\mathrm{P}$} \\
\hline & High expression & High expression & total & & \\
\hline High expression & 29 & 16 & 45 & -0.02 & 0.878 \\
\hline Low expression & 10 & 5 & 15 & & \\
\hline total & 39 & 21 & 60 & & \\
\hline
\end{tabular}

\section{Discussion}

Breast cancer has become the most common cause of cancer-related deaths in women worldwide, and the current treatment for breast cancer mainly relies on surgical resection, supplemented by radiotherapy, chemotherapy, and targeted therapy. Although there are various treatment options, the number of deaths due to breast cancer has not decreased, which may be due to the increase in the prevalence of breast cancer; therefore, the current primary task is to explore the pathogenesis of breast cancer and discover new biomolecular markers and therapeutic targets to effectively predict the progression and prognosis of breast cancer, then achieve early detection, diagnosis, and treatment.

YAP is a transcriptional co-activator, and it is a major regulator of mammalian organ size and cell proliferation, which is highly conserved in mammals and vertebrates. Moreover, YAP is a downstream effector of the mammalian Hippo signaling pathway, which is composed of a core kinase. The activated mammalian sterile 20-like kinase 1 (MST1) or 2 (MST2) binds and phosphorylates the scaffold protein (SAV1). The active MST-SAV1 complex subsequently phosphorylates and activates the large tumor suppressor 1/2 (LATS1/2) and the scaffold protein MOB kinase activator 1A and 1B (MOB1A and MOB1B). Then, the activated LATS-MOB complex phosphorylates and inhibits YAP and the PDZ-binding motif (TAZ), resulting in the inhibition of the Hippo pathway. When the Hippo pathway is inhibited, non-phosphorylated YAP/TAZ can be transported freely to the nucleus, where they can promote the transcription of their target genes, thereby promoting tumorigenesis, proliferation, migration, and apoptosis ${ }^{[17,18]}$. Some studies have confirmed that YAP is highly expressed in cancers of the digestive system, such as esophageal, gastric, liver, colon and pancreatic cancers, so YAP is considered to be an oncogene. In breast cancer research, studies have reported that YAP is highly expressed in breast cancer, but this has always been controversial because some scholars have found that YAP expression is downregulated or absent in breast cancer tissues. Thus, there are still differences in whether YAP is oncogene or tumor suppressor gene. The results of this study show that the expression level of YAP in normal breast tissues is higher than that in breast cancer tissues, which is consistent with the findings of Yuan et $a^{[19]}$. The study of Lamar et al. showed that abnormal YAP expression can activate and drive tumor formation and metastasis, which makes YAP a possible new target for the treatment of breast cancer ${ }^{[17]}$. However, YAP plays an important role in human tissues, so directly targeting YAP may have side effects. Thus, it is necessary to look for target factors that are associated with YAP. In this study, the correlation analysis between YAP and the clinicopathological characteristics of breast cancer patients showed that YAP is related to the Her-2, ER, and PR. This suggests that YAP has an important role in the endocrine or targeted therapy of invasive breast cancer. This study also further tested the expression of YAP in different breast cancer cell lines, and the results showed that YAP was expressed more highly in MCF-7 cells than in MDA-MB-231 cells. MCF-7 is a type of cell line expressing the ER, which further suggests the significance of YAP in the endocrine therapy of breast cancer, and this has been verified by Zhou et al ${ }^{[20]}$; therefore, the results of our study 
indicate that YAP plays a role as a tumor suppressor in the occurrence and development of invasive breast cancer and plays an important role in the treatment of breast cancer.

Wnt signaling is a conservative pathway in the evolution of multicellular animals. Nearly 40 years have passed since the discovery of the Int- 1 proto-oncogene (now called Wnt-1) as the integration site of the mouse breast mammary virus ${ }^{[21]}$. In contrast, breast cancer is the first cancer related to Wnt signaling. Over the past few decades, several studies have shown that Wnt signaling is involved in cell proliferation and metastasis, immune microenvironment regulation, stem cell maintenance, and treatment resistance in cancer, among others, showing strong anti-cancer potential. $\beta$-catenin is the key part of the classic Wnt signaling pathway. When there is no Wnt outside the cell, the Wnt signaling pathway is inhibited, whereas when Wnt exists, Wnt binds to specific Frizzled (FZD) receptors and activates the signaling pathway. The reactive protein binds to leucine-rich repeat-containing G protein-coupled receptor 5 (LGR5) and induces membrane clearance, and with the help of the two, FZD recruits the Disheveled (DVL) protein to the plasma membrane to start the signal transduction in the cell, thus destroying the "destruction complex" composed of adenomatous polyposis coli (APC), Axin, casein kinase 1a (CK1a), and glycogen synthase

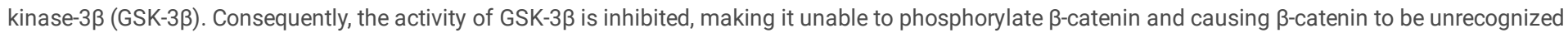
and degraded. As a result, $\beta$-catenin accumulates in the cytoplasm and undergoes nuclear transfer, which will replace the original protein to form a new complex, and finally trigger the expression of the target gene ${ }^{[5]}$. The high expression of $\beta$-catenin in this study was mainly located in the cytoplasmic nucleus, and the expression level in the breast cancer tissues was higher than that in the normal breast tissues. These results were similar to those of Jang et al. ${ }^{[7]}$, wherein compared with normal tissues, the Wnt/ $\beta$-catenin signal activity of the breast cancer tissues was enhanced. In this study, $\beta$-catenin was related to Her2 , suggesting the potential of the Wnt/ $\beta$-catenin signaling pathway in breast cancer-targeted therapy, although no Wnt inhibitor has currently been approved for the treatment of breast cancer. However, the Wnt/ $\beta$-catenin pathway can still provide potential solutions for the basic research and clinical treatment of breast cancer.

The Hedgehog signaling pathway is also a highly conserved signaling pathway, which is essential for normal embryogenesis ${ }^{[22]}$. The Hedgehog signaling pathway has been confirmed to be abnormally activated and highly expressed in many malignant tumors, including small cell lung cancer, medulloblastoma, glioma, melanoma, prostate cancer, ovarian cancer, gastric cancer, and pancreatic cancer ${ }^{[23]}$. Moreover, the Hedgehog pathway has been found to be involved in the regulation of the induction of embryonic mammary glands, the development of duct structures, and the differentiation of the breast during lactation ${ }^{[24]}$. Therefore, abnormal or dysregulation of the Hedgehog signaling pathway is closely related to the ocurrence, development, and metastasis of breast cancer ${ }^{[25]}$ The SMO is one of the core components of the Hedgehog pathway. When the activity of SMO is inhibited, the downstream pathway mediated by SMO will be blocked, and the Hedgehog signaling pathway is in a static state. In contrast, when SMO is activated, the Hedgehog signaling pathway will be further activated. The Hedgehog pathway promotes the growth and development of tumor cells. The core protein, including SMO in the Hedgehog signaling pathway, is highly expressed in breast cancer, which is consistent with the experimental results of our study. In this study, the correlation analysis between SMO and the clinicopathological characteristics of breast cancer patients showed that SMO was related to Her-2, suggesting that SMO may also be of great significance in the process of targeted therapy of invasive breast cancer.

In our study, the expression of YAP, $\beta$-catenin, and SMO in the adjacent breast cancer tissues were analyzed, and the results showed that the expression levels of the three proteins in the adjacent breast cancer tissues was $X$ between those of breast cancer tissues and normal tissues, and the results were not statistically different $(P>0.05)$. However, the results suggest that the expression of protein in paracancerous tissue may be of great significance in breast cancer patients undergoing breast-conserving surgery. The results of a prospective multicenter randomized controlled trial conducted by Dupont et al. showed that removing the extra tissue around the tumor can reduce the marginal positive rate by $50 \%$, and retaining the negative margin is essential to reduce local recurrence ${ }^{[26]}$. Therefore, clarifying the protein expression in the adjacent tissues of the cancer may help clinically confirm an optimal range of surgical resection, which has a significant impact on reducing the recurrence of breast cancer after breast-conserving surgery and promoting the prognosis.

In recent years, the cross-talk between the Hippo and Wnt signaling pathways has been confirmed. These pathways can antagonize tissue cell growth by regulating common components such as YAP and TAZ. For example, phosphorylated YAP/TAZ (through LATS) binds or isolates proteins in the cytoplasm $\beta$ catenin, while dephosphorylated YAP/TAZ promote the nuclear translocation of $\beta$-catenin nuclear translocation ${ }^{[27,28]}$. Some studies have also found that YAP/TAZ is essential for the formation of $\beta$-catenin's "destruction complex" in the absence of Wnt pathway ligands ${ }^{[27]}$. The connection between the Hippo and Wnt pathway is related to the development of breast cancer, but the key intersection point has not yet been fully determined ${ }^{\text {[29] }}$. The experimental results of our study show that there is no significant correlation between YAP and $\beta$-catenin, indicating that the occurrence and development of breast cancer are very complex and may be affected by many factors. Further research is needed on the mechanism of Hippo and Wnt signaling pathway. Our study proved that the expression of YAP and SMO in breast cancer tissues is negatively correlated, suggesting that there may be an interaction between the Hippo and Hedgehog signaling pathways in breast cancer. Zheng et al. found that YAP attenuated dependent glycolysis and tumor growth by promoting the expression of the breast cancer anti-estrogen resistance 4 (BCAR-4). Then, it coordinates with the hedgehog signal to enhance the transcription of glycolysis activators hexokinase 2 (HK2) and 6-phosphofructo-2-kinase/fructose-2, 6-biphosphatase 3 (PFKFB3) and targets BCAR-4 to lock the therapeutic delivery of nucleic acid (locked nucleic acid, LNA) ${ }^{[30]}$. The experimental results of Tariki et al. showed that overexpression of YAP blocks the Hedgehog signaling, and the knockout of YAP can enhance Hedgehog activity ${ }^{[31]}$, which further verified the results of this experiment. The co-activation of Hedgehog and Wnt signaling has been demonstrated in some cancers, including basal cell carcinoma and pancreatic ductal adenocarcinoma ${ }^{[32]}$; however, some studies have shown that the activity of the Wnt/ $\beta$-catenin pathway can be inhibited by the participants of the Hedgehog pathway ${ }^{[33]}$. Therefore, the mutual mechanism of the Hedgehog and Wnt signaling pathways is not yet fully clear, and the results of our study have not found a correlation between the two.

\section{Conclusions}


In summary, three signaling pathways, Hippo, Wnt, and Hedgehog, play an important role in the occurrence, development, diagnosis, and treatment of breast cancer. However, there is no mature theoretical support for the independent diagnosis and treatment of breast cancer. The mechanism of the interaction of the Hippo, Wnt, and Hedgehog signaling pathways in breast cancer is very complicated-the combination of the three may be used as a new direction for breast cancer research in the future, which can open up new paths for molecular-targeted therapy of breast cancer. However, due to the small sample size in this study, it is still unclear whether there are other effects on the expression of YAP, $\beta$-catenin, and SMO, so further research is needed in the future.

\section{Abbreviations}

YAP, Yes-associated protein; SMO, Smoothened; SHH, sonic hedgehog; IHH, Indian hedgehog;

DHH, desert hedgehog; PTCH, transmembrane protein receptor Patched; GLI, glioma-associated oncogene homologue; Glil-3, GLI family zinc finger transcription factors; Runx, residue domain transcription factors; DAB, 3, 3'-diaminobenzidine; HRP, Horseradish peroxidase; BCA, bicinchoninic acid; SDSPAGE, sodium dodecyl sulfate polyacrylamide gel electrophoresis; PVDF, polyvinylidene fluoride; ECL, enhanced chemiluminescence; GAPDH, glyceraldehyde3-phosphate dehydrogenase

OD, optical density; Her-2, human epidermal growth factor receptor 2; ER, estrogen receptor; PR, progesterone receptor; MST1, mammalian sterile 20-like kinase 1; MST2, mammalian sterile 20-like kinase 2; SAV1, scaffold protein; LATS1/2, large tumor suppressor 1/2; MOB1A, MOB kinase activator 1A; MOB1B, MOB kinase activator 1B; TAZ, PDZ-binding motif; FZD, Frizzled; LGR5, leucine-rich repeat-containing G protein-coupled receptor 5; DVL, Disheveled; APC,

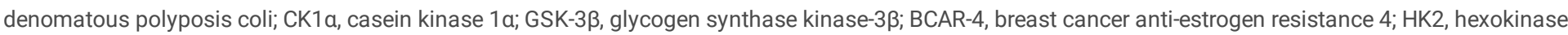
2; PFKFB3, 6-phosphofructo-2-kinase/fructose-2,6-biphosphatase 3; LNA, locked nucleic acid

\section{Declarations}

\section{Acknowledgements}

None

\section{Author contributions:}

(I) Conception and design:P Liu, J Zeng; (II) Administrative support: J Zeng; (III) Provision of study materials or patients: P Liu,G Yang; (IV) Collection and assembly of data: P Liu,G Yang; (V) Data analysis and interpretation: P Liu; (VI) Manuscript writing: All authors; (VII) Final approval of manuscript: All authors.

\section{Funding:}

This study was supported by the Science and Technology Plan Project of Quanzhoou (2019C065R)

\section{Availability of data and materials:}

Data is available from the authors by request.

\section{Ethics approval:}

The study was approved by the ethics committee of the Second Affiliated Hospital of Fujian Medical Universityand(the ethical approval code is [2019](196))

\section{Consent for publication:}

All participants have given consent for publication.

\section{Competing interests:}

The authors declare that they have no competing interests.

\section{References}

1. Bray F, Ferlay J, Soerjomataram I, et al. [J]. CA Cancer J Clin, 2018, 68(6): 394-424.

2. Nandy S B, Gangwani L, Nahleh Z, et al. Recurrence and metastasis of breast cancer is influenced by ovarian hormone's effect on breast cancer stem cells[J]. Future Oncol, 2015, 11(6): 983-95.

3. Shima H, Yamada A, Ishikawa T, et al. Are breast cancer stem cells the key to resolving clinical issues in breast cancer therapy?[J]. Gland Surg, 2017, 6(1): 82-88.

4. Toh T B, Lim J J, Chow E K. Epigenetics in cancer stem cells[J]. Mol Cancer, 2017, 16(1): 29.

5. Xu X, Zhang M, Xu F, et al. Wnt signaling in breast cancer: biological mechanisms, challenges and opportunities[J]. Mol Cancer, 2020, $19(1)$ : 165.

6. Zou Y F, Xie C W, Yang S X, et al. AMPK activators suppress breast cancer cell growth by inhibiting DVL3-facilitated Wnt/ $\beta$-catenin signaling pathway activity[J]. Mol Med Rep, 2017, 15(2): 899-907.

7. Jang G B, Kim J Y, Cho S D, et al. Blockade of Wnt/ $\beta$-catenin signaling suppresses breast cancer metastasis by inhibiting CSC-like phenotype[J]. Sci Rep, 2015, 5: 12465. 
8. Riaz S K, Khan J S, Shah S T A, et al. Involvement of hedgehog pathway in early onset, aggressive molecular subtypes and metastatic potential of breast cancer[J]. Cell Commun Signal, 2018, 16(1): 3.

9. Benvenuto M, Masuelli L, De Smaele E, et al. In vitro and in vivo inhibition of breast cancer cell growth by targeting the Hedgehog/GLI pathway with SMO (GDC-0449) or GLI (GANT-61) inhibitors[J]. Oncotarget, 2016, 7(8): 9250-70.

10. Bhateja P, Cherian M, Majumder S, et al. The Hedgehog Signaling Pathway: A Viable Target in Breast Cancer?[J]. Cancers (Basel), 2019, 11(8):2072-6694

11. Varelas X. The Hippo pathway effectors TAZ and YAP in development, homeostasis and disease[J]. Development, 2014, 141(8): 1614-26.

12. Lamar J M, Stern P, Liu H, et al. The Hippo pathway target, YAP, promotes metastasis through its TEAD-interaction domain[J]. Proc Natl Acad Sci U S A, 2012, 109(37): E2441-50.

13. Guo L, Chen Y, Luo J, et al. YAP1 overexpression is associated with poor prognosis of breast cancer patients and induces breast cancer cell growth by inhibiting PTEN[J]. FEBS Open Bio, 2019, 9(3): 437-445.

14. Quinn H M, Vogel R, Popp O, et al. YAP and B-Catenin Cooperate to Drive Oncogenesis in Basal Breast Cancer[J]. Cancer Res, 2021, 81(8): $2116-2127$.

15. Tariki M, Dhanyamraju P K, Fendrich V, et al. The Yes-associated protein controls the cell density regulation of Hedgehog signaling[J]. Oncogenesis, 2014, 3(8): e112.

16. Xie P, Zhang M, He S, et al. The covalent modifier Nedd8 is critical for the activation of Smurf1 ubiquitin ligase in tumorigenesis[J]. Nat Commun, 2014, 5: 3733.

17. Lamar J M, Xiao Y, Norton E, et al. SRC tyrosine kinase activates the YAP/TAZ axis and thereby drives tumor growth and metastasis[J]. J Biol Chem, 2019, 294(7): 2302-2317.

18. Zhao W, Wang M, Cai M, et al. Transcriptional co-activators YAP/TAZ: Potential therapeutic targets for metastatic breast cancer[J]. Biomed Pharmacother, 2021, 133: 110956.

19. Yuan M, Tomlinson V, Lara R, et al. Yes-associated protein (YAP) functions as a tumor suppressor in breast[J]. Cell Death Differ, 2008, 15(11): 1752-9.

20. Zhou X, Wang S, Wang Z, et al. Estrogen regulates Hippo signaling via GPER in breast cancer[J]. J Clin Invest, 2015, 125(5): 2123-35.

21. Nusse R, Varmus HE. Many tumors induced by the mouse mammary tumor virus contain a provirus integrated in the same region of the host genome[J]. Cell, 1982, 31(1): 99-109.

22. Sari I N, Phi L T H, Jun N, et al. Hedgehog Signaling in Cancer: A Prospective Therapeutic Target for Eradicating Cancer Stem Cells[J]. Cells, 2018, 7(11).

23. Lewis M T, Veltmaat J M. Next stop, the twilight zone: hedgehog network regulation of mammary gland development[J]. J Mammary Gland Biol Neoplasia, 2004, 9(2): 165-81.

24. Hui M, Cazet A, Nair R, et al. The Hedgehog signalling pathway in breast development, carcinogenesis and cancer therapy[J]. Breast Cancer Res, 2013, 15(2): 203.

25. Rajurkar M, De Jesus-Monge W E, Driscoll D R, et al. The activity of Gli transcription factors is essential for Kras-induced pancreatic tumorigenesis[J]. Proc Natl Acad Sci U S A, 2012, 109(17): E1038-47.

26. Dupont E, Tsangaris T, Garcia-Cantu C, et al. Resection of Cavity Shave Margins in Stage 0-III Breast Cancer Patients Undergoing Breast Conserving Surgery: A Prospective Multicenter Randomized Controlled Trial[J]. Ann Surg, 2021, 273(5): 876-881.I

27. Azzolin L, Panciera T, Soligo S, et al. YAP/TAZ incorporation in the $\beta$-catenin destruction complex orchestrates the Wnt response[J]. Cell, 2014, 158(1): 157-70.

28. Imajo M, Miyatake K, limura A, et al. A molecular mechanism that links Hippo signalling to the inhibition of Wnt/ $\beta$-catenin signalling[J]. Embo j, 2012, 31(5): 1109-22.

29. Lim S K, Lu S Y, Kang S A, et al. Wnt Signaling Promotes Breast Cancer by Blocking ITCH-Mediated Degradation of YAP/TAZ Transcriptional Coactivator WBP2[J]. Cancer Res, 2016, 76(21): 6278-6289.

30. Zheng X, Han H, Liu G P, et al. LncRNA wires up Hippo and Hedgehog signaling to reprogramme glucose metabolism[J]. Embo j, 2017, $36(22)$ : 3325-3335.

31. Tariki M, Dhanyamraju P K, Fendrich V, et al. The Yes-associated protein controls the cell density regulation of Hedgehog signaling[J]. Oncogenesis, 2014, 3(8): e112.

32. Yang S H, Andl T, Grachtchouk V, et al. Pathological responses to oncogenic Hedgehog signaling in skin are dependent on canonical Wnt/beta3-catenin signaling[J]. Nat Genet, 2008, 40(9): 1130-5.

33. Schneider F T, Schänzer A, Czupalla C J, et al. Sonic hedgehog acts as a negative regulator of \{beta\}-catenin signaling in the adult tongue epithelium[J]. Am J Pathol, 2010, 177(1): 404-14.

\section{Figures}





Figure 1

The expression trend of YAP, $\beta$-catenin and Smo in breast cancer tissue, Paracancerous tissue and normal tissue

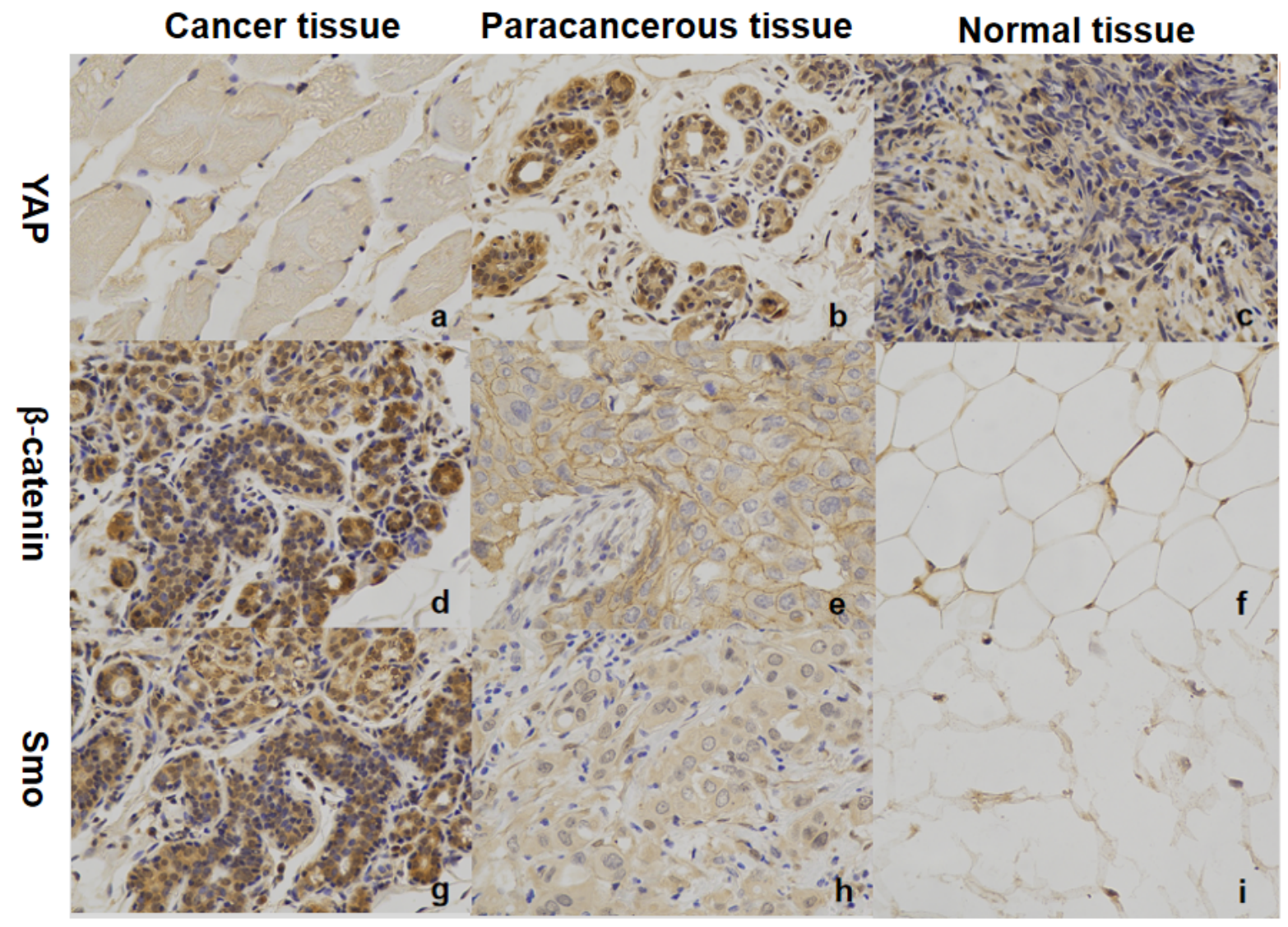

Figure 2

The expression of $\mathrm{YAP} \square \beta$-catenin and Smo in breast cancer tissues,Paracancerous tissues and normal breast tissues(SP staining $₫ 400)$ a:YAP expression in breast cancer tissues is negative or weakly positive(- $₫+)$;b:YAP expression in Paracancerous tissues is weakly positive or moderately positive(+\++);c:YAP expression in normal breast tissue is strongly positive $(+++)$;d: $\beta$-catenin expression in breast cancer tissues is strongly positive(+++);e: $\beta$-catenin expression in Paracancerous tissues is weakly positive or moderately positive(+ $₫++) ; f: \beta$-catenin expression in normal breast tissue is negative(-); $\mathrm{g}:$ Smo expression in breast cancer tissues is strongly positive(+++); $\mathrm{h}: S m o$ expression in Paracancerous tissues is weakly positive or moderately positive(+\++);i:Smo expression in normal breast tissue is negative(-). 
A

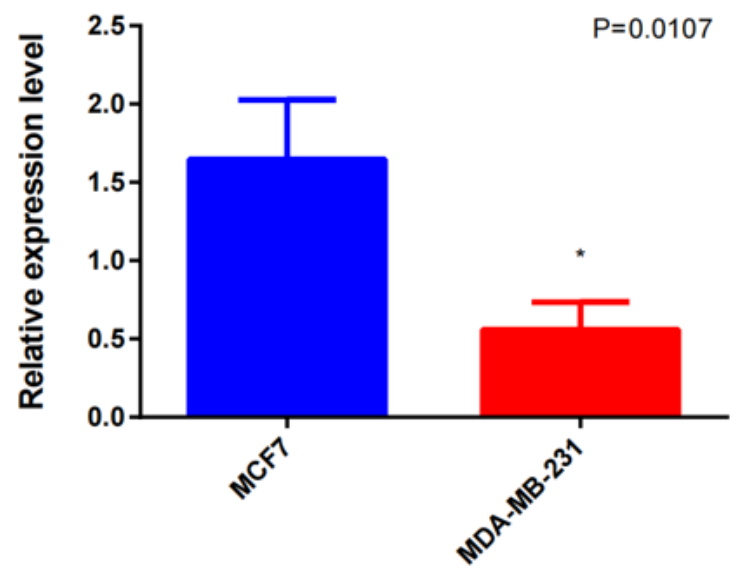

B



Figure 3

Differential expression of YAP between MCF-7 and MDA-MB-231.(A)Difference analysis between MCF-7 and MDA-MB-231;(B)Western blot analysis of MCF-7 and MDA-MB-231. *, $\mathrm{P}<0.05$ compared to the MDA-MB-231 group. 